\title{
Biosynthesis of Membrane Lipids in Rat Axons
}

\author{
Jean E. Vance, ${ }^{\ddagger}$ Debao Pan, ${ }^{* \ddagger}$ Dennis E. Vance, ${ }^{* \S}$ and Robert B. Campenot \\ Lipid and Lipoprotein Research Group, * and the Departments of Medicine, $¥$ Biochemistry, $§$ and Anatomy and Cell Biology,\| \\ University of Alberta, Edmonton, Alberta, Canada T6G 2S2
}

\begin{abstract}
Compartmented cultures of sympathetic neurons from newborn rats were employed to test the hypothesis that the lipids required for maintenance and growth of axonal membranes must be synthesized in the cell body and transported to the axons. In compartmented cultures the distal axons grow into a compartment separate from that containing the cell bodies and proximal axons, in an environment free from other contaminating cells such as glial cells and fibroblasts. There is virtually no bulk flow of culture medium or small molecules between the cell body and axonal compartments. When [methyl- ${ }^{3} \mathrm{H}$ ]choline was added to the cell body-containing compartment the biosynthesis of $\left[{ }^{3} \mathrm{H}\right]$-labeled phosphatidylcholine and sphingomyelin occurred in that compartment, with a gradual transfer of lipids ( $<5 \%$ after $16 \mathrm{~h}$ ) into the axonal compartment. Surprisingly, addition of [methyl$\left.{ }^{3} \mathrm{H}\right]$ choline to the compartment containing only the distal axons resulted in the rapid incorporation of la-
\end{abstract}

bel into phosphatidylcholine and sphingomyelin in that compartment. Little retrograde transport of labeled phosphatidylcholine and sphingomyelin $(<15 \%)$ into the cell body compartment occurred. Moreover, there was minimal transport of the aqueous precursors of these phospholipids (e.g., choline, phosphocholine and CDP-choline) between cell compartments. Similarly, when $\left[{ }^{3} \mathrm{H}\right]$ ethanolamine was used as a phospholipid precursor, the biosynthesis of phosphatidylethanolamine occurred in the pure axons, and $\sim 10 \%$ of the phosphatidylethanolamine was converted into phosphatidylcholine. Experiments with [35S]methionine demonstrated that proteins were made in the cell bodies, but not in the axons. We conclude that axons of rat sympathetic neurons have the capacity to synthesize membrane phospholipids. Thus, a significant fraction of the phospholipids supplied to the membrane during axonal growth may be synthesized locally within the growing axon.
$\mathrm{T}$ THE mechanism of axonal growth and regeneration is generally thought to involve the axonal transport of membrane materials (Toews and Morell, 1985; Ledeen, 1985), such as phospholipids and proteins, from the cell bodies, where these compounds are believed to be synthesized, to the axons (Alberts et al., 1989). However, the question of whether or not axons themselves are capable of the synthesis of membrane lipids has not previously been addressed in pure, intact, living mammalian neurons. Until now it has been diffcult to distinguish lipid production by axons from production by glial cells and other contaminating cell types that invariably associate with axons in vivo.

The synthesis of small amounts of phosphatidylcholine (PtdCho), ${ }^{1}$ phosphatidylethanolamine (PtdEtn), sphingomyelin (SM), and some other lipids has previously been reported in extruded squid axoplasm (Tanaka et al., 1987; Gould et al., 1983a,b). However, extruded squid axoplasm is a highly perturbed preparation. Since the functions of isolated squid axoplasm are rapidly decreasing because of lack of support from the cell bodies, only short incubations with

1. Abbreviations used in this paper: PtdEtn, phosphatidylethanolamine; PtdCho, phosphatidylcholine; SM, sphingomyelin. metabolic precursors are possible. Moreover, the squid axon is unique in its large volume and its origin from many cell bodies rather than from a single cell body. It is therefore quite conceivable that the capacity of squid axons and mammalian axons for the synthesis of phospholipids might be different. Thus, extrapolation of the results to intact mammalian axons is problematical.

Phospholipid metabolism had also previously been studied in mouse sciatic nerves (Gould et al., 1987). In these neurons, when [ $\left.{ }^{32} \mathrm{P}\right]$-labeled phospholipids were subjected to autoradiography no significant phospholipid synthesis was detected in axons, except for the synthesis of some inositol phospholipids. The conclusion from the studies with mouse sciatic nerves (Gould et al., 1987), therefore, conflicted with that from the experiments with squid axoplasm (Tanaka et al., 1987; Gould et al., 1983a,b).

In the present study we provide evidence that significant amounts of the membrane lipids PtdCho, PtdEtn and SM are synthesized by pure, intact, mammalian axons. In contrast, the experiments confirmed the widely-held belief that protein synthesis does not occur in the axons; presumably the proteins required for axonal membrane growth are supplied by the cell bodies. 


\section{Materials and Methods}

\section{Materials}

All radiolabeled chemicals, [methyl $-{ }^{3} \mathrm{H}$ ]choline (specific activity 51 $\mathrm{mCi} / \mathrm{mmol}$ ), $\left[1{ }^{3} \mathrm{H}\right]$ ethanolamine (specific activity $30.4 \mathrm{Ci} / \mathrm{mmol}$ ), and $\left[{ }^{35}\right.$ S]methionine $(1037 \mathrm{Ci} / \mathrm{mmol})$, were purchased from Amersham Corp. (Arlington Heights, IL). All reagents for electrophoresis were from Bio-Rad Laboratories (Cambridge, MA). Thin-layer chromatography plates (silica gel G, $0.25 \mathrm{~mm}$ thickness) were obtained from BDH Chemicals (Edmonton, Canada). The standard phospholipids PtdEtn, PtdCho, and SM were from Avanti Polar Lipids, (Birmingham, AL) or from Sigma Chemical Company (St. Louis, MO). Choline, phosphocholine, CDP-choline, ethanolamine, and phosphoethanolamine were purchased from Sigma Chemical Co., as was BSA, used as carrier protein for the TCA precipitations and as standard for the protein assay.

\section{Culture Materials}

L15 medium without antibiotics (Gibco Laboratories, Grand Island, NY) was supplemented with the additives prescribed by Hawrot and Patterson (1979), including bicarbonate and methylcellulose. Rat serum $(2.5 \%$ provided by the University of Alberta Laboratory Animal Services) and ascorbic acid $(1 \mathrm{mg} / \mathrm{ml})$ were supplied only in medium given to the center compartments containing the cell bodies. Culture medium was changed every 3-6 d. Nonneuronal cells were eliminated by an initial exposure to medium containing $10 \mu \mathrm{M}$ cytosine arabinoside. All three compartments were supplied with nerve growth factor ( $200 \mathrm{ng} 2.5 \mathrm{~S}$ nerve growth factor $/ \mathrm{ml}$ medium)

\section{Preparation of Compartmented Cultures of Neurons}

Using previously described precedures (Campenot, 1979) modified from Hawrot and Patterson (1979), superior cervical ganglia were dissected from newborn rats (Sprague-Dawleys supplied by the University of Alberta Farm), subjected to a combined trypsin and mechanical dissociation procedure and plated into compartmented dishes. The compartmented dishes (Campenot, 1979; Campenot et al., 1991) were constructed from collagencoated $35-\mathrm{mm}$ Falcon tissue culture dishes in which 20 parallel collagen tracks had been formed between scratches in the dish floor from which the dried collagen had been scraped (see Fig. 1). The scratched region of the dish floor was wetted with culture medium, then a Teflon divider, which partitions the dish into three compartments, was sealed to the dish floor with silicone grease. Dissociated sympathetic neurons were plated in the center compartments as previously described (Campenot, 1979; Campenot et al., 1991), and within 1-2 d many neurites had crossed the silicone grease barriers and entered the left and right compartments.

\section{Incorporation of [ $\mathrm{BH}$-labeled Precursors into Phospholipids}

Neurons were cultured for $9 \mathrm{~d}$ as described previously (Campenot, 1979, 1982; Campenot and Draker, 1989). The radioactive phospholipid precursor, either [methyl $\left.{ }^{3} \mathrm{H}\right]$ choline $(10 \mu \mathrm{Ci} / \mathrm{ml})$ or $\left[1-{ }^{3} \mathrm{H}\right]$ ethanolamine $(10$ $\mu \mathrm{Ci} / \mathrm{ml}$ ), was added to each dish in culture medium. $1.0 \mathrm{ml}$ of medium was added to the center compartment containing the cell bodies and proximal axons, and $0.25 \mathrm{ml}$ was added to each side compartment containing the axons. After incubation periods of $1-16 \mathrm{~h}$ the radioactive medium was removed, the cells were washed twice with cold PBS and cellular material was harvested from each compartment in water $(2 \mathrm{ml}$ for the center compartment and $1 \mathrm{ml}$ for each side compartment). The lipids were extracted from a single dish of cells by the addition of chloroform/methanol, 2:1 ( $\mathrm{vol} / \mathrm{vol})$ so that the final ratio of chloroform/methanol/water was $2: 1: 1(\mathrm{vol} / \mathrm{vol})$ (Folch et al., 1959). The lower phase, containing the phospholipids, was washed twice with methanol/water, $1: 1$ (vol/vol) and evaporated to dryness under nitrogen. The lipid samples were applied to a thin-layer chromatography plate which was run in the solvent system chloroform/methanol/acetic acid/formic acid/water, 70:30:12:4:2 (vol/vol) using unlabeled, standard phospholipids as carriers. The bands corresponding to authentic standards of PtdCho, PtdEtn, and SM were scraped from the plate and counted for radioactivity.

\section{Incorporation of [3H]-labeled Precursors into Water-soluble Metabolites}

The aqueous extract (containing choline, phosphocholine, CDP-choline, ethanolamine, phosphoethanolamine, and CDP-ethanolamine) from the lipid extraction was retained and evaporated to dryness (Pritchard and Vance, 1981). The residue was redissolved in methanol/water, 1:1 (vol/vol) and subjected to thin-layer chromatography, whereby the metabolites were separated in a solvent system consisting of ammonia/methanol $/ 0.6 \% \mathrm{NaCl}$, 5:50:50 (vol/vol) (Pritchard and Vance, 1981). The spots corresponding to authentic choline, phosphocholine, CDP-choline, ethanolamine, phosphoethanolamine, and CDP-ethanolamine were scraped from the plates and radioactivity was counted.

\section{Incorporation of [35S]Methionine into Proteins}

$\left[{ }^{35} \mathrm{~S}\right]$ Methionine $(250 \mu \mathrm{Ci} / \mathrm{ml})$ was added to either the cell body- or axoncontaining compartments of 9-d-old cultures. After $16 \mathrm{~h}$ the medium was removed and the cells were washed twice with cold PBS. Combined cellular material from three cultures was harvested into PBS. BSA $(1 \mathrm{mg})$ was added to each sample as a carrier. Proteins were precipitated by the addition of an equal volume of $20 \%$ (wt/vol) TCA (final concentration of TCA was $10 \%$ ), and a pellet was obtained by centrifugation at $3,000 \mathrm{~g}$ for $15 \mathrm{~min}$. The pellet was washed three times with cold 5\% TCA. Proteins were solubilized from the pellet by the addition of $0.5 \mathrm{ml}$ of buffer containing $6 \mathrm{M}$ urea and 2\% SDS (Vance et al., 1984). Each sample was electrophoresed on a 3-15\% gradient polyacrylamide gel containing $0.1 \%$ SDS (Vance et al., 1984). The gel was fluorographed by exposure to a photographic plate for $3 \mathrm{~d}$ at $-70^{\circ} \mathrm{C}$.

\section{Results}

\section{Establishment of the Cell Culture System}

Sympathetic neurons from newborn rats were plated in the center compartments of collagen-coated culture dishes con-

a Compartmented culture

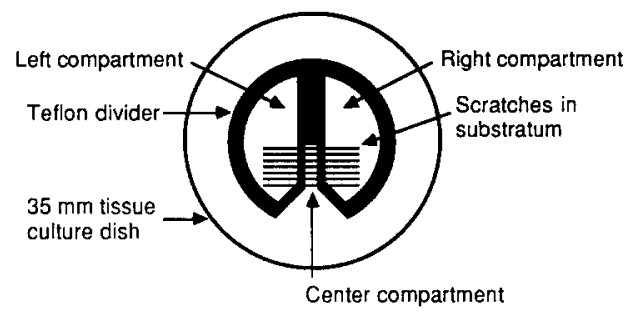

b Enlargement of a single track

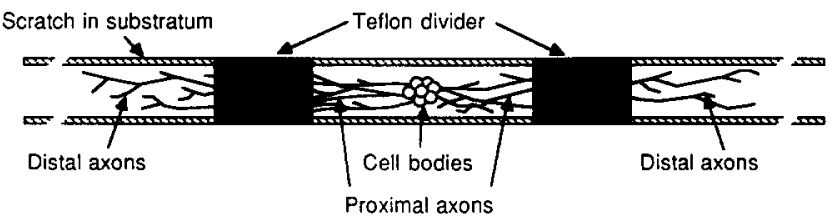

Figure 1. A compartmented culture showing (a) an entire culture and $(b)$ enlargement of a single tract. Dissociated neurons were plated in the center compartment (density about one ganglion per dish). Neurites extended to the left and right compartments, under silicone grease barriers and into separate fluid environments. The tracks were formed on the collagen-coated floor of a 35-mm plastic tissue culture dish between a series of parallel scratches from which the dried collagen substratum had been scraped. Each track is $\sim 200 \mu \mathrm{m}$ wide, the center compartments are $\sim 1 \mathrm{~mm}$ wide, and the barriers are about $\sim 0.5 \mathrm{~mm}$ wide. One culture contains up to 20 tracks occupied by neurons. The distal neurites are harvested by mechanically rinsing neurites from the left and right compartments with a jet of distilled water delivered with a syringe and a 22-gauge hypodermic needle. Left and right samples are pooled. Cell bodies and proximal neurites are harvested by removal of the Teflon divider after the distal neurites have been removed, and all remaining material is collected. 
taining a Teflon divider which formed three compartments (Fig. 1). Axons extended under the silicone grease barriers and into the left and right compartments. The neuron cultures were maintained for $9 \mathrm{~d}$ in the presence of $8 \mathrm{nM} 2.5 \mathrm{~S}$ nerve growth factor; nonneuronal cells were eliminated by treatment for the first $6 \mathrm{~d}$ with cytosine arabinoside, as previously described (Campenot, 1979, 1982; Campenot and Draker, 1989). The center compartment contained cell bodies and proximal axons, whereas the left and right compartments contained distal axons alone, with no cell bodies. Each compartment contained a separate fluid environment since there is virtually no bulk flow of culture medium (Campenot, 1982) or significant diffusion of small molecules such as ions (Campenot and Draker, 1989) between compartments. Moreover, when a $\left[{ }^{3} \mathrm{H}\right]$-labeled phospholipid precursor was supplied directly to one compartment, little or no radioactivity was detected in the medium of the other compartments during the course of the experiment.

Development of the unique three-compartment model has provided a means by which, for the first time, metabolic events occurring in axons alone can be studied independently of those occurring in the cell bodies.

\section{Biosynthesis of Phosphatidylcholine and Sphingomyelin from [Methyl- $\left.{ }^{3} \mathrm{H}\right]$ choline in Axons and Cell Bodies of Rat Neurons}

The biosynthesis of two of the major lipid components of axons (PtdCho and SM) was investigated by the addition of [methyl- ${ }^{3} \mathrm{H}$ ]choline, a radiolabeled precursor of these two phospholipids, to either the center compartment containing the cell bodies and proximal axons, or to the left and right compartments containing only distal axons. Radiolabeled lipids were isolated from each compartment and radioactivity was measured (Fig. 2). As expected, when [methyl$\left.{ }^{3} \mathrm{H}\right]$ choline was added to the cell body-containing compartment, radioactive PtdCho (Fig. 2 a) and SM (Fig. 2 c) were rapidly produced in that compartment. Small amounts of both radioactive lipids (after $16 \mathrm{~h}<5 \%$ of the amount of radioactivity of the same lipids in the cell bodies) were apparently transported into the distal axons. However, unexpectedly, when [methyl- ${ }^{3} \mathrm{H}$ ]choline was added to the axoncontaining compartments alone, radioactive PtdCho (Fig. 2 b) and SM (Fig. $2 d$ ) rapidly appeared in the axons. No more than $15 \%$ of the $\left[{ }^{3} \mathrm{H}\right]$-labeled PtdCho and SM of the axons was present in the cell body-containing compartment, even after $16 \mathrm{~h}$.

Analysis of the major $\left[{ }^{3} \mathrm{H}\right]$ choline-labeled water-soluble precursors of PtdCho (choline, phosphocholine and CDPcholine) in the axon- and cell body-containing compartments, from the experiment described above, and depicted in Fig. 2, is shown in Fig. 3. The pattern of labeling of the water-soluble metabolites followed closely that of the lipid product PtdCho. The data showed a lack of equilibration of the water-soluble intermediates between the cell body- and axon-containing compartments, at least for the $16 \mathrm{~h}$ duration of the experiment. For example, even $16 \mathrm{~h}$ after $\left[{ }^{3} \mathrm{H}\right]$ choline had been added to the axon compartments the radioactivity in choline, phosphocholine, and CDP-choline in the cell body compartment was only 9,19 , and $19 \%$, respectively, of the radioactivity of the same intermediates in the axons.

Fig. 3 demonstrates that $\left[{ }^{3} \mathrm{H}\right]$ choline rapidly enters the cells and subsequently the $\left[{ }^{3} \mathrm{H}\right]$ choline decreases in both the cell body- and axon-containing compartments, approxi-

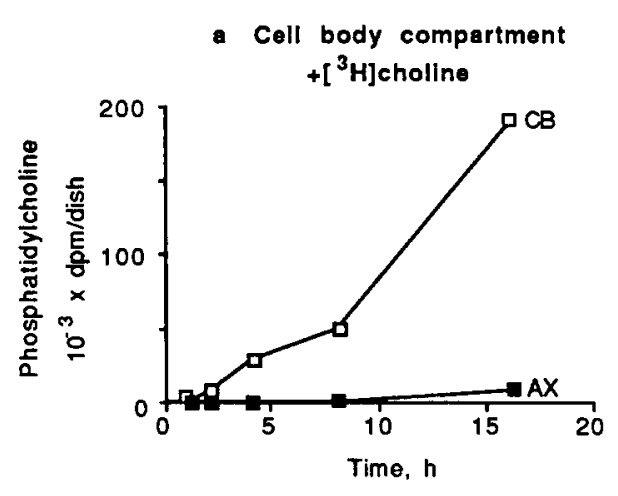

c Cell body compartment $+\left[{ }^{3} \mathrm{H}\right]$ choline

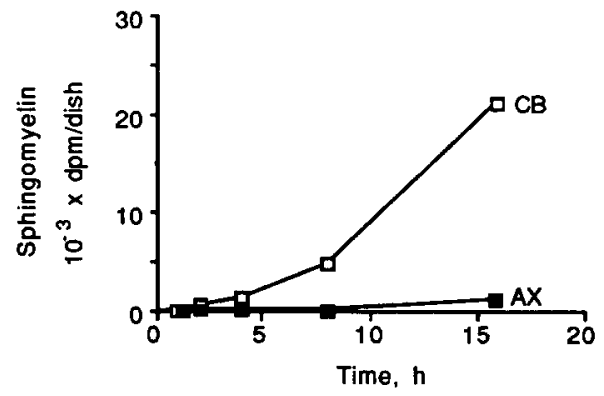

b Axon compartment $+\left[{ }^{3} \mathrm{H}\right]$ choline

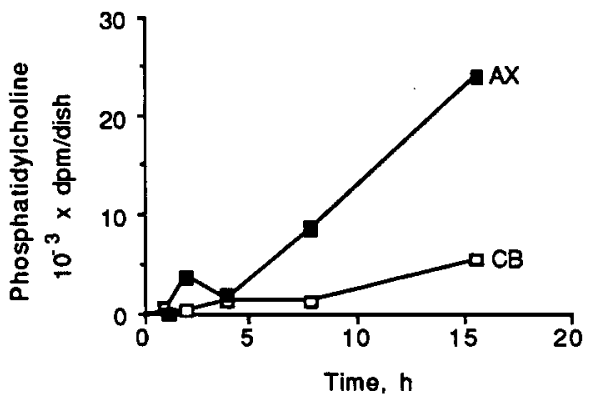

d Axon compartment $+\left[{ }^{3} \mathrm{H}\right]$ chollne

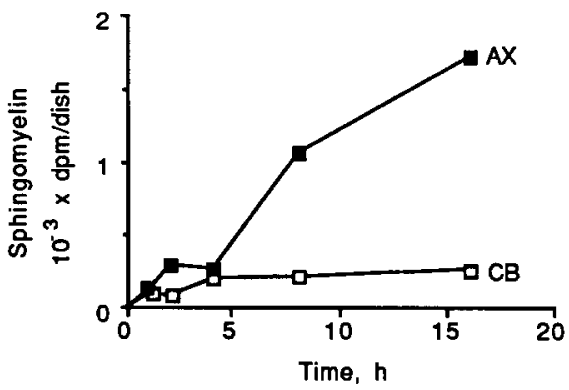

Figure 2. Axonal biosynthesis of PtdCho and SM-[Meth$\left.\mathrm{yl}-{ }^{3} \mathrm{H}\right]$ choline $(10 \mu \mathrm{Ci} / \mathrm{ml})$ was added to either the cell bodycontaining compartments (a and $c$ ) or the axon compartments $(b$ and $d)$ of isolated rat sympathetic neurons that had been cultured for $9 \mathrm{~d}$. At the indicated times, the cellular material from each compartment was collected in water and pelleted by ultracentrifugation. The lipids were extracted and PtdCho ( $a$ and $b$ ) and SM ( $c$ and $d$ ) were isolated by thin-layer chromatography. Radioactivity in PtdCho and SM was determined by scintillation counting. (open symbols) $\left[{ }^{3} \mathrm{H}\right]$ in cell bodycontaining compartments $(C B)$; (filled symbols) $\left[{ }^{3} \mathrm{H}\right]$ in axoncontaining compartments $(A X)$. Each point is the average of two individual cultures. All data for each experiment were collected from sister cultures. The experiment was repeated three times with similar results. 


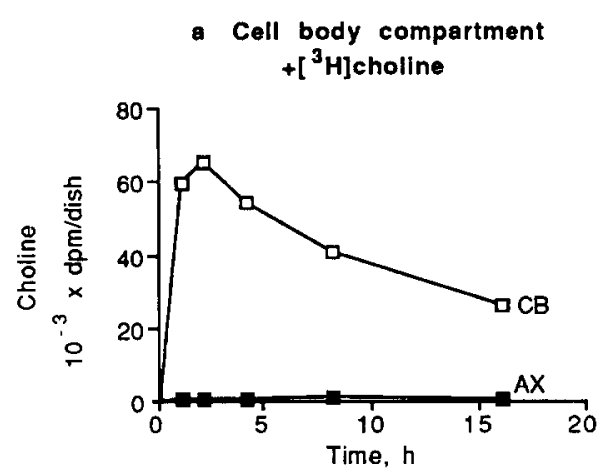

c Cell body compartment $+\left[{ }^{3} \mathrm{H}\right]$ cholline

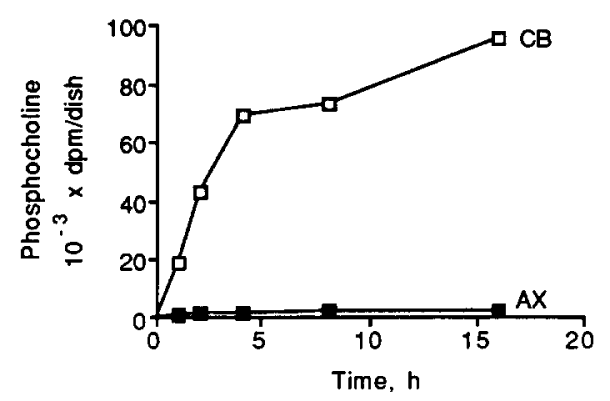

e Cell body compartment $+\left[{ }^{3} \mathrm{H}\right]$ choline

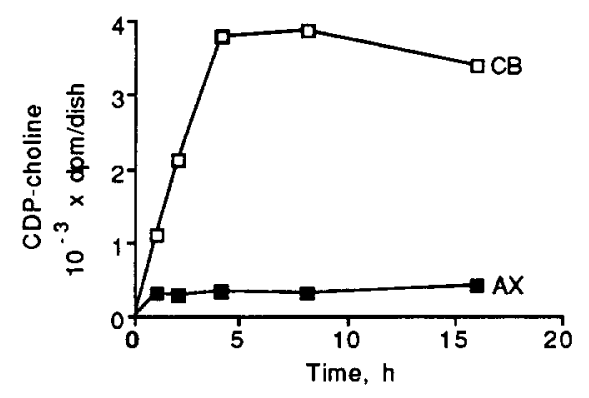

b Axon compartment $+\left[{ }^{3} \mathrm{H}\right]$ choline
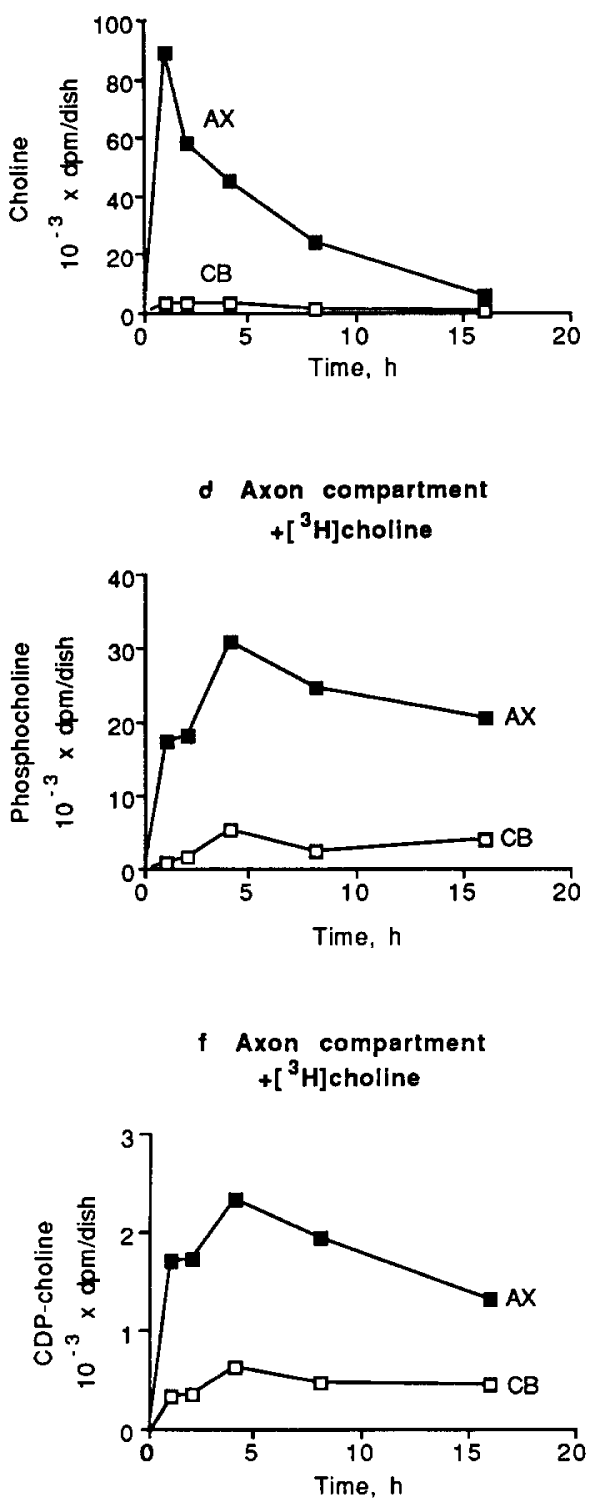

Figure 3. Incorporation of $\left[\right.$ methyl $\left.{ }^{3} \mathrm{H}\right]$ choline into water soluble metabolites. From the experiments depicted in Fig. 2 the lipids were extracted and the metabolites in the aqueous phase from the lipid extraction were isolated by thin-layer chromatography in the solvent system ammonia/methanol/ 0.6\% NaCl, 5:50:50 (vol/vol).

The spots corresponding to authentic standards of choline ( $a$ and $b$ ), phosphocholine ( $c$ and $d$ ) and CDP-choline ( $e$ and $f$ ) were scraped from the plates and radioactivity was measured. Each point is the average of two individual cultures. Three additional similar experiments were performed with similar results. All data for each experiment were collected from sister cultures. (open symbols) $\left[{ }^{3} \mathrm{H}\right]$ in cell body-containing compartments $(C B) ;$ (filled symbols) $\left[{ }^{3} \mathrm{H}\right]$ in axon-containing compartments $(A X)$. mately in parallel. Radioactivity from choline subsequently appears in phosphocholine, and then in PtdCho and SM. The data presented in Fig. 3 are from one representative experiment of four that were performed. Although the amount of $\left[{ }^{3} \mathrm{H}\right]$ choline used in the four experiments was not identical, and there was some variation in the time points at which samples were harvested, basically similar results were obtained from each experiment. In one experiment, methylcellulose was included in the growth medium which altered the results slightly, presumably due to sticking of $\left[{ }^{3} \mathrm{H}\right]$ choline to the cell surface (data not shown). In the other two experiments the decrease in $\left[{ }^{3} \mathrm{H}\right]$ choline in the axon compartment between 2 and $8 \mathrm{~h}$ was 40 and $52 \%$. In the cell body compartment the decrease in radioactive choline over the same time period was 30 and $38 \%$. Although the reason for the rapid decrease in $\left[{ }^{3} \mathrm{H}\right]$ choline labeling is not clear, the phenomenon was consistently observed in both the axon and cell body compartments.
In rat liver the enzyme that produces CDP-choline (i.e., CTP:phosphocholine cytidylyltransferase) is, under many metabolic conditions, the rate-limiting enzyme for PtdCho biosynthesis (Vance, 1990). In the neuronal cultures used in the present experiments the amount of radioactivity in CDPcholine was at all times much lower than that in phosphocholine. For example, $8 \mathrm{~h}$ after the addition of $\left[{ }^{3} \mathrm{H}\right]$ choline to the cell body-containing compartment the radioactivity in CDP-choline in the cell body compartment was 3,860 $\mathrm{dpm} /$ dish, whereas the radioactivity in phosphocholine was $72,720 \mathrm{dpm} /$ dish. Similarly, $8 \mathrm{~h}$ after $\left[{ }^{3} \mathrm{H}\right]$ choline had been added to the axon compartment the radioactivity in CDPcholine in the axon compartment was $1,950 \mathrm{dpm} / \mathrm{dish}$, and in phosphocholine was $24,650 \mathrm{dpm} / \mathrm{dish}$. These experiments suggest that the "bottleneck" in the PtdCho biosynthetic pathway in the neurons may be at the stage of production of CDPcholine from phosphocholine, and that CTP:phosphocholine cytidylyltransferase may be the rate-limiting enzyme of 
PtdCho biosynthesis in both the cell body- and axoncontaining compartments of the cultured neurons.

These data demonstrate that PtdCho and sphingomyelin were efficiently biosynthesized in axons. In addition, there was not a rapid equilibration of the radiolabeled phospholipids, or their water-soluble precursors, between the axons and the cell bodies.

\section{Synthesis of Proteins in Compartmented Cultures}

Since it is generally agreed that neuronal proteins are made only in cell bodies (Toews and Morell, 1985; Ledeen, 1985; Alberts et al., 1989), and not in axons, protein synthesis was investigated in the three compartment model. $\left[{ }^{35} S\right]$ Methionine was added to either the cell body-containing compartment or to the axon-containing compartments for $16 \mathrm{~h}$ at which time cellular material was harvested from each compartment. Proteins were isolated and subjected to electrophoresis on a 3-15\% gradient polyacrylamide gel containing $0.1 \%$ SDS. The gel was fluorographed and the radiolabeled proteins are illustrated in Figure 4. As anticipated, when ${ }^{35}$ S]methionine was added to the cell body compartment radiolabeled proteins were observed in that compartment, with some radiolabeled proteins being apparently transported into the axons. In contrast, when [ ${ }^{35}$ S]methionine was added to the axon compartments alone, no $\left[{ }^{35} \mathrm{~S}\right]$-labeled proteins were detected either in the axon- or cell body-containing compartments. These data support the hypothesis that proteins required for axonal growth are synthesized in the cell bodies, and that no detectable protein synthesis occurs in axons. The data also demonstrate the effectiveness of the compartment model for separation of metabolic events occurring in the individual compartments.

\section{Biosynthesis of Phosphatidylethanolamine and Phosphatidylcholine from $\left[{ }^{-3} \mathrm{H}\right]$ ethanolamine in Axons and Cell Bodies}

Although the majority of PtdCho in all mammalian cells that have been examined is synthesized by the CDP-choline pathway (Vance, 1990), an alternative biosynthetic route for PtdCho exists in which PtdEtn is methylated to PtdCho by three successive $\mathrm{N}$-methylation reactions (Vance and Ridgway, 1988). In addition, in mammalian cells PtdEtn is synthesized by two major pathways: from CDP-ethanolamine (via a pathway analogous to the CDP-choline pathway for PtdCho synthesis [Kennedy and Weiss, 1956]) and via the decarboxylation of phosphatidylserine (Dennis and Kennedy, 1972). In experiments similar to those described for the studies on PtdCho and SM biosynthesis from $\left[{ }^{3} \mathrm{H}\right]$ choline (Figs. 2 and 3), $\left[1-{ }^{3} \mathrm{H}\right]$ ethanolamine was used as a precursor of PtdEtn and PtdCho. $\left[{ }^{3} \mathrm{H}\right]$ Ethanolamine was incorporated into PtdEtn (Fig. 5, $a$ and $b$ ) in both the cell body- and axon-containing compartments. Similarly, the methylation of $\left[{ }^{3} \mathrm{H}\right]$-labeled PtdEtn to PtdCho occurred in each of the compartments containing the cell bodies (Fig. $5 c$ ) and the axons (Fig. $5 d$ ). The time lag shown in Fig. $5(c$ and $d$ ) for the labeling of PtdCho compared with PtdEtn was longer than expected, one possible explanation for which is that there may be a compartmentalization of PtdEtn synthesis and PtdEtn methylation in both the axon and cell body compartments. The data presented in Fig. 5 are from one experiment that is representative of two additional similar experiments.

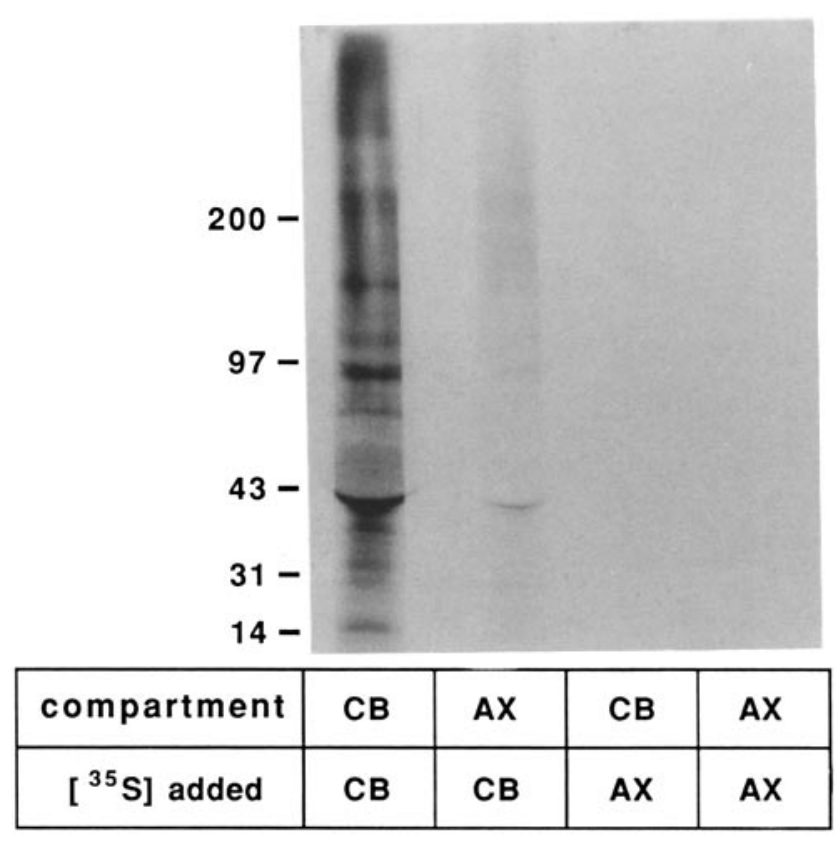

Figure 4. Biosynthesis of proteins in cell bodies but not axons. [ ${ }^{35}$ S] Methionine $(250 \mu \mathrm{Ci} / \mathrm{ml})$ was added for $16 \mathrm{~h}$ to either the cell body-containing compartment $(C B)$ or the axon-containing compartments $(A X)$ of isolated rat sympathetic neurons. Cellular material from three cultures combined was harvested from the individual compartments. After the addition of albumin as a protein carrier the proteins were precipitated with TCA. Proteins were solubilized by heating the pellet in an extraction buffer containing $6 \mathrm{M}$ urea and $2 \%$ SDS. Each sample was subjected to electrophoresis on a 3-15\% gradient polyacrylamide gel containing $0.1 \%$ SDS. The gel was fluorographed by exposure to a photographic plate for $3 \mathrm{~d}$ at $-70^{\circ} \mathrm{C}$. The numbers to the left of the gel represent molecular masses $\left(\times 10^{-3} \mathrm{kD}\right)$ of standard proteins. The experiment was repeated twice with similar results. Each lane contains the total protein from three dishes of cells, either from the center compartments or from the two side compartments combined. The amount of radioactivity applied to each lane of the gel was $225,621,22,212$, 1,845 , and $1,521 \mathrm{dpm}$, from the left lane to the right lane of the gel.

Although there were some variations in the amounts of radioactivity added to the cells and the time points at which the samples were collected, the conclusions were the same from all three experiments. For example, the increased incorporation of $\left[{ }^{3} \mathrm{H}\right]$ ethanolamine into PtdCho between 8 and $16 \mathrm{~h}$ was apparent in all experiments. In the two experiments for which the data are not given, the increase in $\left[{ }^{3} \mathrm{H}\right] \mathrm{PtdCho}$ in the cell body compartment during this time period was 2.1and 4.9-fold, whereas in the axon compartments was 4.4and 6.7 -fold. By $16 \mathrm{~h}$ of incubation with the radiolabeled precursor, $\sim 6$ and $11 \%$ of the PtdEtn in the axon and cell body compartments, respectively, had been methylated to PtdCho. This is the most efficient conversion of PtdEtn to PtdCho that has been reported for cells other than hepatocytes (Vance and Ridgway, 1988).

The water-soluble precursors of PtdEtn were isolated by thin-layer chromatography from the incubations described in the legend to Fig. 5. The distribution and labeling patterns of two of the intermediates of PtdEtn biosynthesis from ethanolamine in the cell body- and axon-containing compartments (i.e., ethanolamine and phosphoethanolamine) are 
a Cell body compartment $+\left[{ }^{3}\right.$ H]ethanolamine

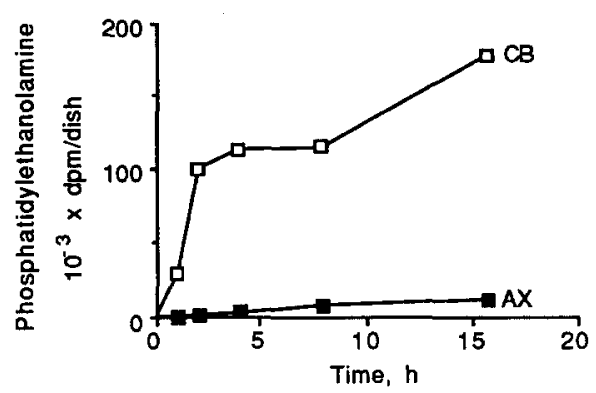

c Cell body compartment $+\left[{ }^{3} \mathrm{H}\right]$ ethanolamine

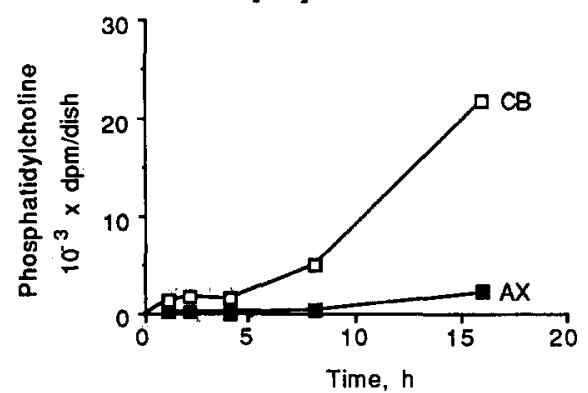

b. Axon compartment

$+\left[{ }^{3} \mathrm{H}\right]$ ethanolamine

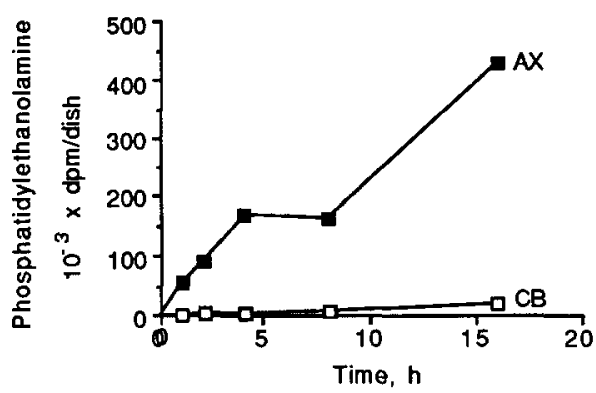

d Axon compartment $+\left[{ }^{3} \mathrm{H}\right]$ ethanolamine

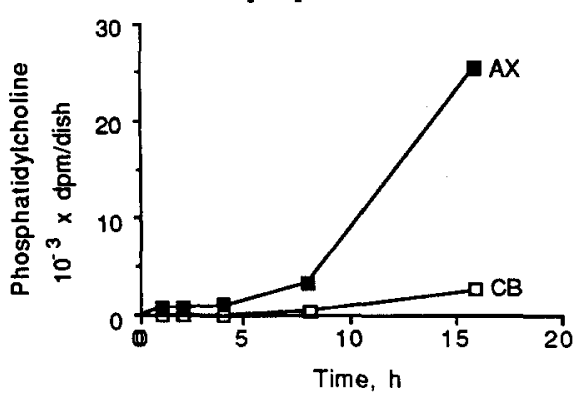

Figure 5. Axonal biosynthesis of PtdEtn and PtdCho from $\left[1-{ }^{3} \mathrm{H}\right]$ ethanolamine. $\left[1-{ }^{3} \mathrm{H}\right]-$ Ethanolamine $(10 \mu \mathrm{Ci} / \mathrm{ml})$ was added to either the cell body-containing compartment ( $a$ and $c$ ) or the axon-containing compartments ( $b$ and $d$ ) of isolated rat sympathetic neurons. The experiment was performed as described in Fig. 2 except that $\left[{ }^{3} \mathrm{H}\right]$ ethanolamine, instead of $\left[{ }^{3} \mathrm{H}\right]$ choline was used. PtdEtn ( $a$ and $b$ ) and PtdCho ( $c$ and $d$ ) were isolated by thin-layer chromatography. (open symbols) $\left[{ }^{3} \mathrm{H}\right]$ in cell body compartments $(C B)$; (filled symbols) $\left[{ }^{3} \mathrm{H}\right]$ in axon compartments $(A X)$. Each point is the average of two individual cultures. All data for each experiment were collected from sister cultures. Two additional similar experiments were performed with similar results. presented in Fig. 6. As was observed for the $\left[{ }^{3} \mathrm{H}\right]$ choline metabolites (Fig. 3), the $\left[{ }^{3} \mathrm{H}\right]$ ethanolamine-labeled intermediates were largely confined to the compartments to which the $\left[{ }^{3} \mathrm{H}\right]$ ethanolamine had been added. The incorporation of $\left[{ }^{3} \mathrm{H}\right]$ ethanolamine into $\mathrm{CDP}$-ethanolamine was lower than that into ethanolamine or phosphoethanolamine, but the pattern of labeling was similar for all three ethanolamine metabolites. For example, when radioactivity was added to the cell body-containing compartment, after $16 \mathrm{~h}$ there were $16,980 \mathrm{dpm}$ in CDP-ethanolamine in that compartment and 1,580 dpm in the axon compartments. Similarly, when $\left[{ }^{3} \mathrm{H}\right]$ ethanolamine was added to the axon compartments, CDP-ethanolamine in those compartments contained 11,220 dpm, whereas in the center compartment there were 2,720 dpm in CDP-ethanolamine after $16 \mathrm{~h}$.

The data presented in Figs. 5 and 6 demonstrate that in axons, as well as in cell bodies, PtdEtn is actively synthesized from $\left[{ }^{3} \mathrm{H}\right]$ ethanolamine and that the PtdEtn is efficiently methylated to PtdCho. The experiments using $\left[{ }^{3} \mathrm{H}\right]$ choline (Figs. 2 and 3 ) and $\left[{ }^{3} \mathrm{H}\right]$ ethanolamine (Figs. 5 and 6) in combination demonstrate that axons alone have the capacity for synthesis of the three major phospholipids of axonal membranes - PtdEtn, PtdCho, and SM.

\section{Discussion}

These experiments show for the first time that significant amounts of the principal lipid components of cell membranes, PtdCho, PtdEtn, and SM, can be synthesized by living, intact axons under conditions in which the neurons can grow and be maintained indefinitely. In contrast, but in agreement with currently accepted ideas, proteins were synthesized only in the cell body-containing compartment; there was no detectable synthesis of proteins by the axons.

The apparent biosynthesis of PtdCho, PtdEtn, and SM in the axons could not be explained by leakage or diffusion of the radiolabeled precursors from the axon compartment into the cell body-containing compartment since there is virtually no flow of culture medium (Campenot, 1982; Campenot and Draker, 1989) or radioactive precursors between the compartments. Nor could radioactivity in PtdCho, PtdEtn, and $\mathrm{SM}$ in the axons have been produced by retrograde axonal transport of radiolabeled precursors from the cell body compartment into the axon compartments, followed by biosynthesis of the lipid within the cell bodies, and subsequent anterograde movement of the phospholipid products into the axons. When $\left[{ }^{3} \mathrm{H}\right]$ choline or $\left[{ }^{3} \mathrm{H}\right]$ ethanolamine was added to the axons, the radioactivity in both the water-soluble precursors of the phospholipids, and in the phospholipids themselves, was at all times much higher in the axons than in the cell body-containing compartment.

Indeed, the transport of both the phospholipid products and the water-soluble precursors of PtdCho and PtdEtn, between the cell body- and axon-containing compartments was surprisingly slow in both directions. Cultures raised under conditions similar to those used in the present experiments were assayed for protein using a silver-binding assay for measurement of nanogram quantities of protein (Krystal, 1987). Preliminary results indicated that the cultures each contained $\sim 1 \mu \mathrm{g}$ neuronal protein and that the center compartments (cell bodies plus proximal axons) contained 5 to 10 times more protein than did the left and right compart- 

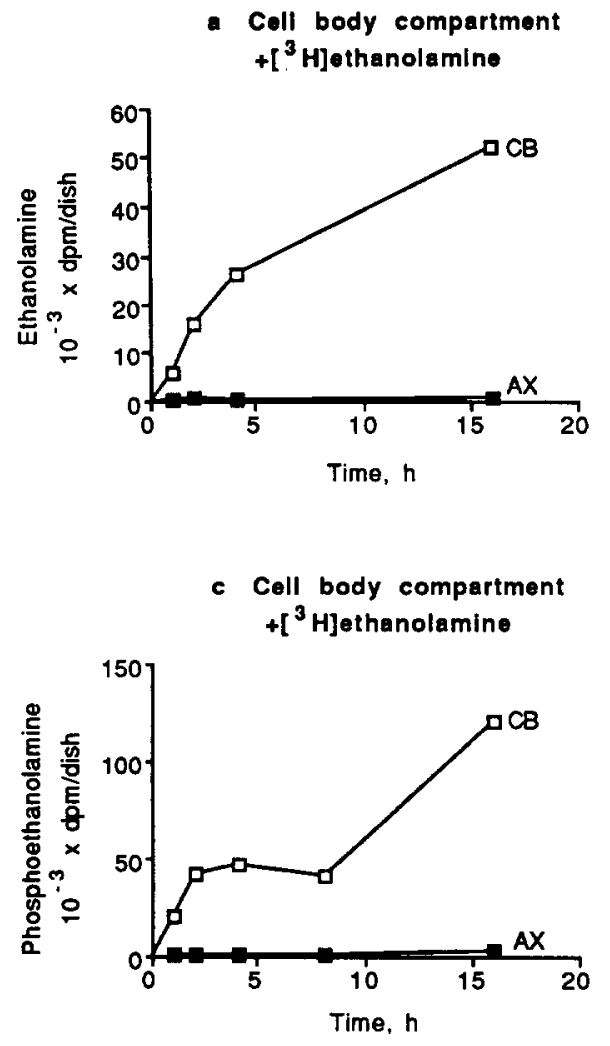
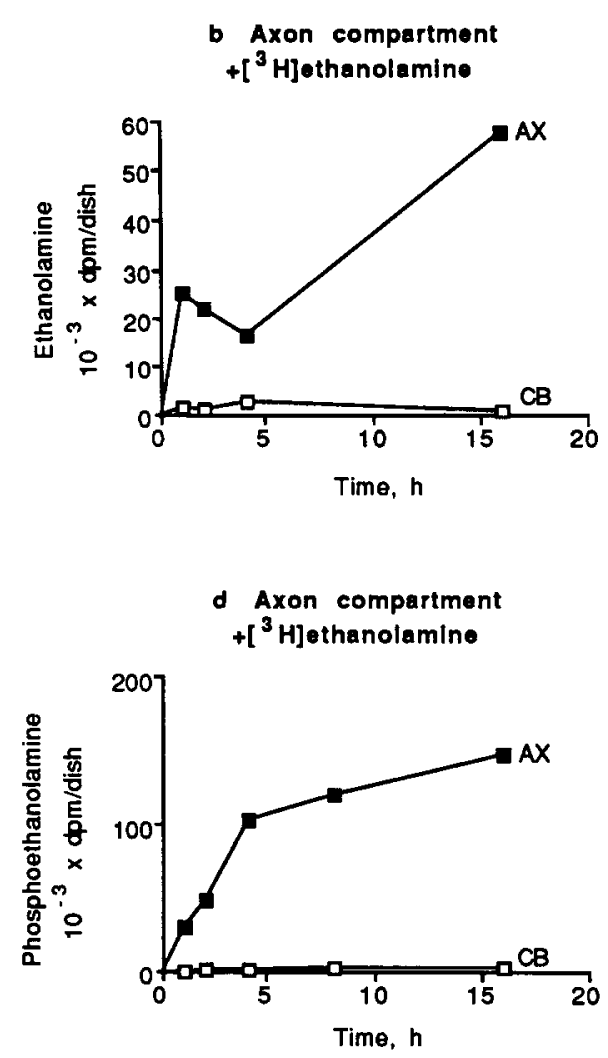

Figure 6. Incorporation of $\left[1-{ }^{-} \mathrm{H}\right]$ ethanolamine into watersoluble metabolites. The lipids were extracted from the neuron samples used for the experiments depicted in Fig. 5. The metabolites in the aqueous phase from the lipid extraction were isolated by thinlayer chromatography. The spots corresponding to authentic standards of ethanolamine $(a$ and $b$ ) and phosphoethanolamine $(c$ and $d)$ were scraped from the plates and radioactivity was measured. (open symbols) $\left[{ }^{3} \mathrm{H}\right]$ in cell body-containing compartments. $(C B)$; (filled symbols) $\left[{ }^{3} \mathrm{H}\right]$ in axon compartments $(A X)$. ments (distal axons) combined. The amounts of proteins measured were very small and therefore this result must be interpreted with caution because some nerve growth factor, as well as proteins from the serum supplied to center compartments, may have adhered to the cells. Nonetheless, the majority of the neuronal material apparently resided in the center compartment. Consequently, even if the incorporation of $\left[{ }^{3} \mathrm{H}\right]$ choline into PtdCho and SM, or of $\left[{ }^{3} \mathrm{H}\right]$ ethanolamine into PtdEtn and PtdCho, in the present experiments were considered on the basis of radioactivity per milligram cell protein, the data show that only a minor fraction of the phospholipids produced in either compartment was transported into the other compartment. Although small amounts of those lipids were apparently axonally transported in both directions, after $16 \mathrm{~h}$ of incubation with the radiolabeled precursor the $\left[{ }^{3} \mathrm{H}\right.$ ]phospholipids had not equilibrated among the center and side compartments.

Attempts made to label phospholipids of the neurons with $\left[{ }^{3} \mathrm{H}\right.$ ]glycerol were unsuccessful, apparently because there was minimal uptake of this precursor by the cells.

From the present investigation a revised picture of the mechanism of axonal growth and regeneration has emerged. In the cultured neurons used the axons were presumably elongating at a rate of $\sim 1 \mathrm{~mm} /$ day (Campenot and Draker, 1989), which requires a massive input of newly made phospholipids and proteins. The proteins are apparently supplied by the cell bodies as confirmed in the present study. In contrast, however, phospholipids are synthesized in both the cell body- and axon-containing compartments. The experiments presented here raise the possibility that membrane lipids required for axonal growth and regeneration may be supplied, at least in part, by lipids synthesized in situ in the axons.
Therefore, an understanding of the regulation of the axonal production of lipids is of prime importance in our knowledge of how nerve fibers grow and regenerate.

We thank Dwight D. Draker and Grace Dotto for excellent technical assistance and Richard A. Murphy for providing $2.5 \mathrm{~S}$ nerve growth factor.

This work was supported by grants from the Medical Research Council of Canada. R. B. Campenot is a Medical Scholar, and D. E. Vance is a Medical Scientist, of the Alberta Heritage Foundation for Medical Research.

Received for publication 23 May 1991 and in revised form 26 July 1991.

\section{References}

Alberts, B., D. Bray, J. Lewis, K. Roberts, and J. D. Watson. 1989. In Molecular Biology of the Cell. 2nd edition. Garland, New York and London. 1113. Campenot, R. B. 1979. Independent control of the local environment of somas and neurites. Methods Enzymol. 28:302-307.

Campenot, R. B. 1982. Development of sympathetic neurons in compartmentalized cultures. I. Local control of neurite growth by nerve growth factor. $D e v$. Biol. 93:1-12.

Campenot, R. B., and D. D. Draker. 1989. Growth of sympathetic nerve fibers in culture does not require extracellular calcium. Neuron. 3:733-743.

Campenot, R. B., A. H. Walji, and D. D. Draker. 1991. Effects of sphingosine, staurosporine, and phorbol ester on neurites of rat sympathetic neurons growing in compartmented cultures. J. Neurosci. 11:1126-1139.

Dennis, E. A., and E. P. Kennedy. 1972. Intracellular sites of lipid synthesis and the biogenesis of mitochondria. J. Lipid Res. 13:263-267.

Folch, J., M. Lees, and G. H. Sloane-Stanley. 1959. A simple method for the isolation and purification of total lipids from animal tissues. J. Biol. Chem. 226:497-509

Gould, R. M., H. Pant, H. Gainer, and M. Tytell. 1983a. Phospholipid synthesis in the squid giant axon: incorporation of lipid precursors. J. Neurochem. 40:1293-1299.

Gould, R. M., W. D. Spivak, D. Robertson, and M. J. Poznansky. $1983 b$. Phospholipid synthesis in the squid giant axon: enzymes of phosphatidylinositol metabolism. J. Neurochem. 40:1300-1306.

Gould, R. M., J. Holshek, W. Silverman, and W. D. Spivak. 1987. Localization of phospholipid synthesis to Schwann cells and axons. J. Neurochem. 
48: $1211-1231$.

Hawrot, E., and P. H. Patterson. 1979. Long-term cultures of dissociated sympathetic neurons. Methods Enzymol. 28:574-584.

Krystal, G. 1987. A silver-binding assay for measuring nanogram amounts of protein in solution. Anal. Biochem. 167:86-96.

Kennedy, E. P., and S. B. Weiss. 1956. The function of cytidine coenzymes in the biosynthesis of phospholipides. J. Biol. Chem. 222:193-214.

Ledeen, R. W. 1985. Transport, exchange, and transfer of phospholipids in the nervous system. In Phospholipids in Nervous Tissues. J. Eichberg, editor. John Wiley \& Sons Inc. New York, 135-172.

Pritchard, P. H., and D. E. Vance. 1981. Choline metabolism and phosphatidylcholine biosynthesis. Biochem. J. 196:261-267.

Tanaka, T., H. Yamaguchi, Y. Kishimoto, and R. M. Gould. 1987. Lipid metabolism in various regions of squid giant nerve fiber. Biochim. Biophys.
Acta. 922:85-94.

Toews, A. D., and P. Morell. Axonal transport of phospholipids. In Phospholipids in the Nervous System. Vol. 2. Physiological Roles. 1985. L. A. Horrocks, J. N. Kanfer, and G. Porcellati, editors. Raven Press, New York. 299-314.

Vance, D. E. 1990. Phosphatidylcholine biosynthesis: masochistic enzymology, metabolic regulation and lipoprotein assembly. Biochem. Cell Biol. 68:1151-1165

Vance, D. E., and N. D. Ridgway. The methylation of phosphatidylethanolamine. 1988. Prog. Lipid Res. 27:61-79.

Vance, D. E., D. B. Weinstein, and D. Steinberg. 1984. Isolation and analysis of lipoproteins secreted by rat liver hepatocytes. Biochim. Biophys. Acta. 792:39-47. 